Session \# 1464

\title{
TEACHING ABOUT MICROMECHANICS OF FRACTURE AND OTHER FAILURE ANALYSIS APPROACHES FOR BIOMATERIALS
}

\author{
K.V. Sudhakar, Tadeusz Majewski \\ Department of Mechanical Engineering, \\ Universidad de las Americas-Puebla, \\ Santa Catarina Martir, Puebla 72820, Mexico
}

\begin{abstract}
This paper discusses some of the relevant teaching methodologies and supplemental experimental tools for studying biomaterials. Austenitic Stainless Steel (316L grade) and Vitallium-2000 Plus (Cobalt-Chrome alloy) metallic biomaterials that are commonly in Artificial Hip Joint (AHJ) and Partial Orthodontic Dentures (POD), respectively, are studied. Teaching methods discussed in this paper include; discussion model approach, lecture quiz approach, and learning outside the class room approach. A study on micromechanics of fracture is performed using a JEOL microprocessor controlled Scanning Electron Microscope (SEM-Model JSM 5910 LV). The characterization techniques include Back Scattered Image (BSI), Secondary Electron Image (SEI), Topography of fracture surface, and Energy Dispersive X-ray analysis (EDAX) for studying the fracture surface morphologies of biomaterials. High and low magnification photomicrographs of the fracture surface at several locations are taken to understand the possible mechanisms responsible for the fracture, in both materials. The other failure analysis approaches/methods include destructive and non-destructive tests. Specific experimental procedures for destructive tests (namely, tensile test, hardness, and charpy impact toughness) are developed to suit the exact biomaterial geometries. Microindentation testing procedure is followed to determine the fracture toughness of especially the thin sections of Vitallium partial orthodontic dentures. In this technique, microindentations are made on the polished surface of thin sections of biomaterials using a diamond indenter. The other method involves direct measurement of indentation size (from this the fracture toughness estimation) from the formation of a stable crack. Next, the experimental procedures for carrying out the microstructure studies (specimen polishing, specific etchant and chemical etching procedures) are developed to study the microstructural details in fractured biomaterials. The present detailed and systematic studies bring out the practically useful class-room teaching and supplemental experimental approaches/tools for understanding and analyzing failures in any given biomaterial. Specific
\end{abstract}

"Proceedings of the 2004 American Society for Engineering Education Annual Conference \& Exposition Copyright (C) 2004, American Society for Engineering" 
methods/procedures are also discussed to evaluate the course by assessing students' performance and effectiveness of the course.

Keywords: Teaching tools; Biomaterials; Micromechanics of fracture; Failure analysis approaches; Methods of course assessment.

\section{Introduction}

The late 19th century ushered in the concept of aseptic surgery, and with refinement of this principle came the possibility of implanting foreign materials into the body with an acceptably low risk of rejection due to infection. However, at this time there existed no suitable material to withstand the challenges posed by the biologic environment, particularly in regard to strength and corrosion resistance. Developments in metal refining and processing in the first half of the 20th century, stimulated largely by wartime needs, led to the production of improved materials that were rapidly, although empirically, adapted by surgeons for use in fracture fixation. The materials currently popular are those that over the years have performed "acceptably" in clinical situations, and only recently (within the past 20 years) has the introduction of the field of biomaterials research had an influence on subsequent technologic advances in this regard. Biomaterials are nonviable materials used in a medical device intended to interact with biological systems ${ }^{1}$. One of the prime requirements is biocompatibility that is the ability of a material to perform with an appropriate response in a specific application ${ }^{1}$. Biomaterials include implant devices, drug delivery, biosensors, bioseparation, cell/tissue/organ culture, animal husbandry, aquaculture and the biochip. In all these cases, the common theme is interaction between biosystem and synthetic or modified natural materials.

Stainless steel alloy presently recommended for device manufacture is the American Iron and Steel Institute (AISI) type 316L. The exact composition may vary slightly relative to the casting or forging variant; however, both forms are derived from the very common 18-8 stainless steel alloy (18\% chromium, $8 \%$ nickel) used in tableware and other commercial applications. The composition differences between the 18-8 and 316L alloy are necessitated by the superior corrosion resistance required of implant devices. Very briefly, the addition of molybdenum (3\%) to the $18-8$ alloy and the reduction of carbon content ( $0.03 \%$ max $)$ confer improved corrosion resistance particularly to pitting and intergranular attack, respectively. Such compositional changes, however, necessitate the addition of nickel (12\%) to maintain the stability of the desired microstructure, austenite.

The cleanliness or purity of the refined implant stainless steel alloy may influence greatly the corrosion resistance and mechanical properties. All steels contain impurities or non-metallic inclusions, which by design are minimized to obtain the desired combination of properties for implantation purposes. Many manufacturers recommend further alloy refinement processes such as vacuum arc remelting and electro-slag refining to optimize implant performance. Although a cast stainless steel alloy is produced, the vast majority of stainless steel devices used to day is manufactured from the wrought alloy owing to the generally improved mechanical properties and reduced impurity content. It is estimated from retrieval studies that stainless steel alloys constitute approximately $60 \%$ of the implants used in the United States. The science of

"Proceedings of the 2004 American Society for Engineering Education Annual Conference \& Exposition Copyright (C) 2004, American Society for Engineering" 
biomaterials, by liberal definition, encompasses all materials of biologic composition or for biologic application. For purposes of this chapter, however, the designation "orthopedic biomaterials" will be synonymous with "materials used for internal fracture fixation." Excellent reviews tracing the history of biomaterials development and describing state-of-the-art technology have been published and should be consulted for more in-depth information on this subject ${ }^{1-7}$.

The introduction of Vitallium-2000 Plus material provides physical and mechanical properties never before attainable in chrome cobalt alloys. Vitallium-2000 Plus incorporates a controlled nitrogen addition during the con-cast process, which results in a yield and tensile strength and elongation higher than any other chrome cobalt alloy on the market. The improved physical properties provide extraordinary strength and unprecedented fracture resistance while allowing for smaller, lighter, more delicate partial frameworks. Vitallium-2000 Plus also has increased flexibility, without deformation or fracture, allowing for excellent adjustability similar to that of gold. By far, Vitallium-2000 Plus produces the most refined, smooth surface available, one that is easier to adjust, maintains its luster and resists plaque while still maintaining that legendary Vitallium precision fit. Vitallium-2000 Plus is the premium alloy of choice for the ultimate partial denture.

A study on micromechanics of fracture is very important to understand and evaluate the failure behavior of biomaterials. This paper discusses the relevant teaching methods and also the supplemental experimental procedures used in a team-taught course.

\section{TEACHING METHODS}

\subsection{Undergraduate course on biomaterials and its role in the curriculum}

A typical biomaterial course taught for the undergraduate students with special emphasis on micromechanics of fracture and failure analysis approaches include the following contents namely, course objectives, learning objectives and methodology for teaching. This course is offered as an elective for undergraduate students. The students studying this course usually have preliminary background in materials science, manufacturing process and basic mechanics. The typical strength of students in this course is 15 to 20 . This course is very useful for preparing mechanical/materials engineers with sound knowledge of specialty materials like biomaterials.

\subsubsection{Course objectives}

Material/biomaterial selection is a challenging task in developing a medical device. Many factors, often competing, need to be considered. They include mechanical properties, biocompatibility, microstructure, micromechanics of fracture, production costs, and ease of manufacturing apart from others that may be important depending on a specific situation. This course familiarizes the student with relevant material issues and highlights the process for matching material performance with the design of a particular medical device. The students' knowledge of biomaterials will be increased and an appreciation for the relationships between a material's structure, its properties, and the implementation of properties to achieve a desired

"Proceedings of the 2004 American Society for Engineering Education Annual Conference \& Exposition Copyright (C) 2004, American Society for Engineering" 
functionality will be developed. Failure analysis approaches are discussed (theory and practice) to enhance student's knowledge on biomaterials.

\subsubsection{Learning objectives}

Upon successful completion of this course, the student will be able to:

- Identify the MERITS and DEMERITS of a given class of materials regarding their use in medical devices.

- Select a suitable/appropriate biomaterial for a given medical device.

- Factor the strengths and weaknesses of a biomaterial into the design of a medical device.

- Explain/Model/Describe the micromechanics of fracture in biomaterials.

- Gain hands-on experience in learning the methodologies of failure analysis in biomaterials.

\subsubsection{Course methodology}

Instruction is followed by an interactive lecture style format. Inclusion of a series of guest lecturers increases the breadth of knowledge presented. The first half of the semester concentrates on basic mechanical testing, microstructure including micromechanics of fracture and on the properties of materials, including biological tissues. The second half of the semester is more applications oriented, with particular emphasis on understanding the usage of metallic implants. Failure analysis is studied in greater detail with a special emphasis on case studies.

\subsection{Discussion model approach in teaching biomaterials}

A discussion model is used to understand and discuss the topic "micromechanics of fracture and failure analysis techniques" used for biomaterials. This model aims to make small-group discussion more meaningful and effective in light of limited spatial resources and growing class sizes. Typical class size is 20 . The course structure involved 2-hr class discussions that compliment $3 \mathrm{hr}$ weekly lectures. During each session, the 20 students' discussion group is divided into subgroups of 5 students; each sub-group is given 1 or 2 topics (under which specific problems are highlighted) to discuss. After 15 minutes of preparation, the sub-groups are encouraged to debate/discuss the issues with each other; the professor acts as a discussion facilitator and summarizes key issues raised during the 2-hr discussion.

\subsection{Lecture quiz approach}

Lecture quizzes are introduced as a continual assessment component. Typically, 10-15 short questions (demanding specific answers) in the form of multiple-choice, true/false or computation are asked in each lecture quiz. Students are allowed to discuss the questions and hand in the answers in small groups. The main aim of the lecture quiz is to let the lecturer have a better gauge of whether the students have grasped the main concept taught in each lecture on specialty topics like biomaterials. It also promotes cooperative learning among the students as well as allows them to relate to and reflect instantly on what they have just learned.

"Proceedings of the 2004 American Society for Engineering Education Annual Conference \& Exposition Copyright (C) 2004, American Society for Engineering" 


\subsection{Learning outside the classroom (especially for learning failure analysis approaches)}

Many scholars program modules offer students opportunities to learn outside the classroom, apply theoretical concepts learnt in class, and have these concepts challenged through practical application. This practice is very vital especially for learning failure analysis techniques. Ideally, team teaching utilizes the coordinated expertise of several faculty members to achieve a common course goal. This pedagogical method is widely practiced in many universities worldwide, especially in the engineering/science discipline, where one modular subject matter often covers a wide array of specialized topics.

At its best, team teaching provides the students with a wide range of challenging and eyeopening viewpoints on a broad subject matter expounded by different faculty members who themselves are the experts and authorities in their area of specialization. At its worst, it becomes a disorganized and confusing presentation of unrelated and contradicting information. In addition, it can become an excuse for the teacher to evade his teaching responsibilities.

Here are some fundamental rules to follow to achieve a successful team teaching endeavor:

- To be effective, the teaching team must have a dedicated coordinator who has a clear curricular vision of the module.

- The choice and sequence of delivery of topics should be agreed upon beforehand among the participating faculty with the coordinator in the leadership role.

- The coordinator should make the course goal and lecture timetable clear to the students on the first day of the class.

- The topical discussion at each class meeting should reflect and relate to the main theme of the modular subject matter.

- There is some truth to the adage that too many cooks spoil the broth. Ideally, a teaching team should not consist of more than three lecturers.

- The coordinator should attend, at least during the first time of the course implementation, all of the lectures.

- It is mandatory that the coordinator should always maintain a proper overview of the modular offer to assure topical correlation and synthesis of the knowledge with help from the students.

- The full attendance of the coordinator also assures that the final exam questions can be comprehensively constructed to evaluate fairly and objectively the learning outcomes expected from the students.

- All participating faculty members should be repeatedly made aware that the success of the team-taught module depends on the combined effectiveness of the team performance.

- In planning the tutorials, it is best to involve and divide the responsibility among members of the teaching team, instead of passing the assignment to other department staff.

- It is necessary and important for the coordinator to do internal control and adjustment should a disruption arise during the semester owing to the failure of a team member to deliver the anticipated performance.

"Proceedings of the 2004 American Society for Engineering Education Annual Conference \& Exposition Copyright (C) 2004, American Society for Engineering" 
- Most importantly, because of the limited number of lecture hours assigned to each of the team members, the course coordinator becomes the only person who has the opportunity during the semester to build good rapport between the teaching group and the students that is essential and a pre-requisite to an effective learning environment.

\section{EXPERIMENTAL METHODS}

Various experimental methods (though not directly linked to the topics discussed in teaching methods of this paper) for learning about biomaterials are studied as additional tools to evaluate the failure behavior of biomaterials. Instructional lectures on each experimental method are given during each group's (having maximum 5 students) laboratory classes. Each group has one laboratory class of $3 \mathrm{hrs}$ duration per week. A written laboratory report is required to be turnedin by the students before the commencement of next experiment/laboratory class. The ultimate goal of these practical exercises is to provide hands-on experience for students in analyzing fracture behavior in biomaterials. Also, we strongly believe that these laboratory exercises help students in developing their learning, analyzing and creative thinking skills/abilities.

As already mentioned in the course methodology (section 2.1.3), mechanical testing including microindentation hardness testing, fracture toughness testing, ball punch deformation test, inclusion analysis are all carried out in the first half of the semester. Detailed studies on micromechanics of fracture in biomaterials are carried out in the second half of the semester.

\subsection{Microindentation hardness testing (ASTM E384-99)}

Typically, TEN microhardness measurements are made on the samples by each group of students. In the present case, testing was considered to be light force since the size of indentations (diagonal length) is less than $20 \mu \mathrm{m}$. Thus, hardness numbers obtained from indentations with diagonals measuring less than $20 \mu \mathrm{m}$ are much more sensitive to variations of a few tenths of a micrometer in the actual or measured length of the diagonals than hardness numbers obtained by measuring larger indentations. Vitallium alloy, due to its very small size required mounting. Sufficient care is taken to ensure that the specimens are well supported in the mounting material. Also, the surface to be tested is placed into the test instrument such that it is normal to both the loading and optical axis. The optical quality of the microscope is such that highly corrected objectives with numerical apertures of 0.9 and greater are used. In addition, dark field illumination and differential interference contrast is used to improve the contrast of the image. This also helps to enhance the user's ability to detect the ends of the indentations.

Microvickers hardness tests are carried out using Shimadzu microhardness testing machine using a load of 100g. The procedure adopted for this test is as per the standard ASTM-E384. The Vickers hardness (HV) is calculated using the formula:

$$
\mathrm{HV}=1854.4 \mathrm{P} / d^{2}
$$


Where the load $\mathrm{P}$ is in grams-force and the average diagonal $d$ is in $\mu \mathrm{m}$. The Vickers hardness value is constant over a very wide test load range for a homogeneous material due to geometrically similar indentations.

\subsection{Experimental determination of fracture toughness}

TWO fracture toughness tests are performed by each student group. Plane strain fracture toughness $\left(\mathrm{K}_{\mathrm{IC}}\right)$ is a materials parameter of considerable engineering significance. The American Society for Testing Materials (ASTM) has developed detailed procedures for determining $\mathrm{K}_{\mathrm{IC}}$. Frequently, a standard compact test (CT) specimen is used to experimentally determine the fracture toughness of materials. The critical value of $\mathrm{K}$ at fracture is calculated using the expression:

$\mathrm{K}_{\mathrm{IC}}=\left(\mathrm{P}_{\mathrm{f}} / \mathrm{BW}^{1 / 2}\right) \mathrm{f}(\mathrm{a} / \mathrm{w})$ where

$\mathrm{P}_{\mathrm{f}}$ is the fracture load, $\mathrm{B}$ is the specimen thickness, $\mathrm{W}$ is the specimen width, and $\mathrm{f}(\mathrm{a} / \mathrm{w})$ is a calibration function/correction factor. Variations of this procedure are recommended for polymers, ceramics and very thin metallic wires where the considerations for loads, rates and gripping are quite difficult. To obtain toughness values for very thin materials like the present orthodontic wires, a test very similar to the hardness test is frequently used.

\subsection{Ball punch deformation test procedure to evaluate formability (ASTM E643-2000)}

THREE ball punch deformation tests are carried out by each group of students. The ball punch deformation test is widely used to evaluate and compare the formability of metallic sheet materials. Biaxial stretching is the predominant mode of deformation occurring during the test. However, precise correlations between the cup height as determined by this test and the formability of a sheet material under production conditions have not been established.

Erichson cup testing machine equipped to hold about $10 \mathrm{kN}$ was used for this test. A minimum of three tests are carried out for each test. The speed of the penetrator is $0.2 \mathrm{~mm} / \mathrm{s}$, but the speed is reduced to lower the limit in order to more accurately determine the end point. The preferred method for determining is by the drop-in load on the specimen. In general this indicates the onset of necking in the dome. Since the size of the test specimen in the present case is very small, sufficient care is taken to determine the end point. Comparison of ball punch deformation test results shows compliance with the specification of biomaterials regarding formability characteristics.

\subsection{Determining the inclusion content by automatic image analysis ${ }^{8}$ (ASTM E1245-2000)}

TWO measurements are performed for assessing the inclusion content by a students group. The indigenous or second phase constituents in stainless steel are viewed with a light microscope and scanning electron microscope using a suitably prepared metallographic specimen. The image is detected using a television-type scanner tube (solid state or tube camera) and displayed on a high resolution video monitor. Inclusions are detected and discriminated based on their gray-level

"Proceedings of the 2004 American Society for Engineering Education Annual Conference \& Exposition Copyright (C) 2004, American Society for Engineering" 
intensity differences compared to each other and the unetched matrix. Measurements are made based on the nature of the discriminated picture point elements in the image ${ }^{8}$. These measurements are made on each field of view selected. Statistical evaluation of the measurement data is based on the field-to-field or feature-to-feature variability of the measurements.

\subsection{Micromechanics of fracture on SS nails for shinbone and Vitallium alloy}

Every student is encouraged to actively participate during this study on micromechanics of fracture. Fractured surfaces of biomaterials are studied using SEM JEOL Model JSM 5910 LV. The techniques used include topography, secondary electron image (SEI), back scattered electron image (BSI) and analysis of micro-constituents using EDAX technique. Some of the typical fractographs are shown in Figure 1 through 3.

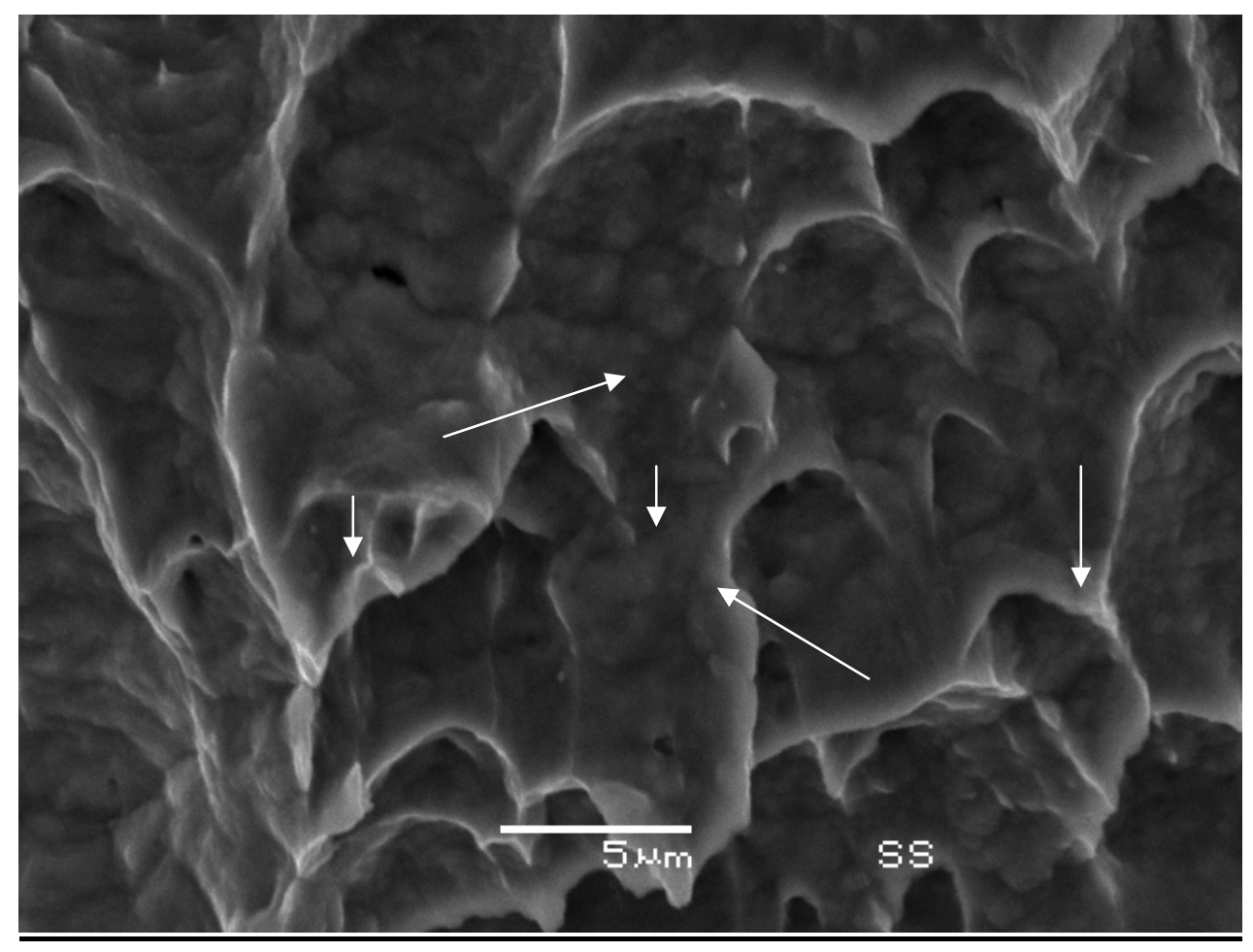

Fig. 1 Fracture surface (crack propagation) demonstrating a highly ductile fracture in SS alloy 


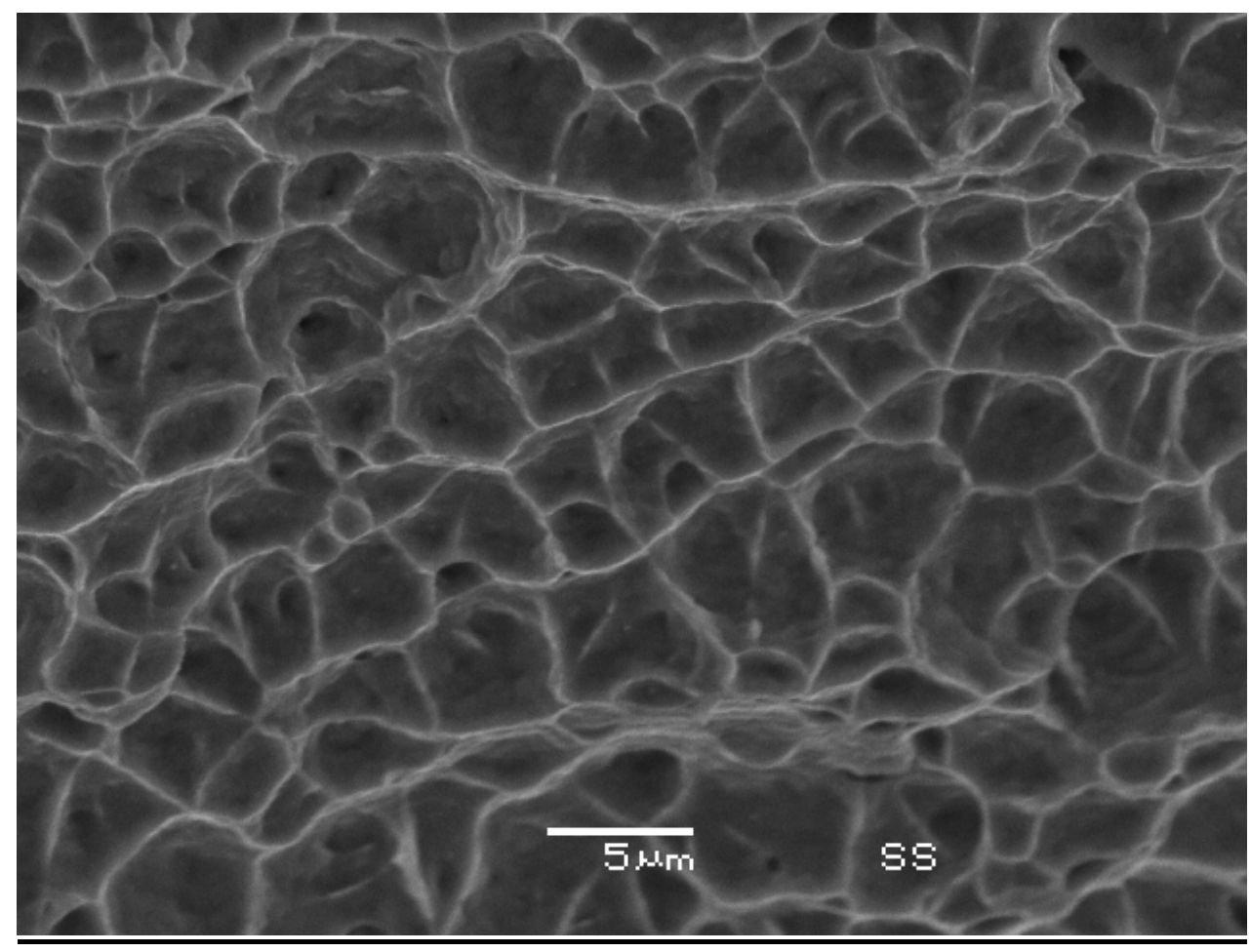

Fig. 2 Presence of dimples characteristic of ductile fracture at final fracture zone in Vitallium alloy

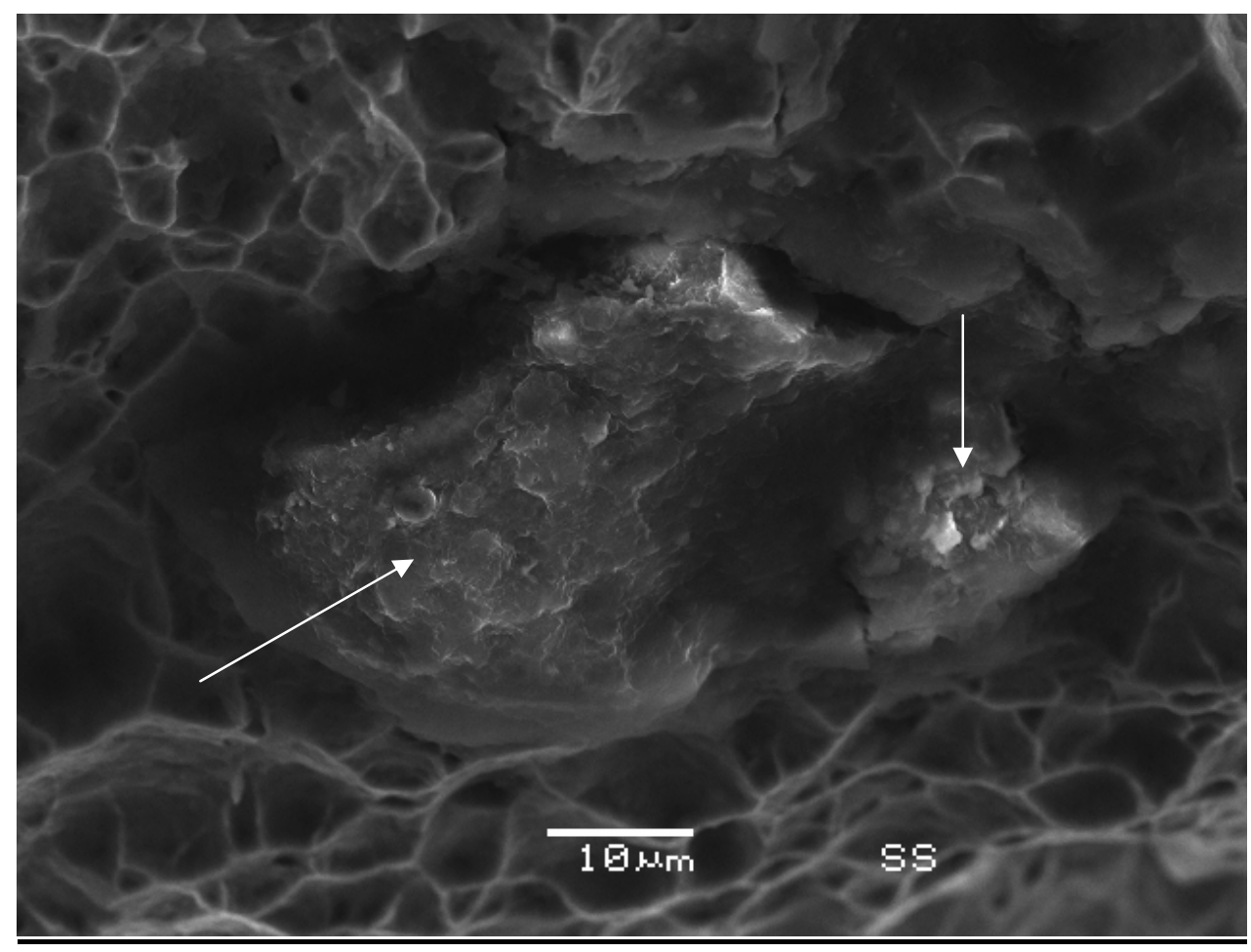

Fig. 3 Presence of a non-metallic inclusion in SS alloy

"Proceedings of the 2004 American Society for Engineering Education Annual Conference \& Exposition Copyright $\left({ }^{\circ}\right.$ 2004, American Society for Engineering" 


\section{Methods of assessment}

The following methods are used to assess student's performance and the effectiveness of the course.

\subsection{Student performance}

In lecture classes, 3 tests (one each month), 2 quizzes, one final, and a final project are given in a semester to assess the performance of students.

Typical laboratory quizzes, each of about 15 min (containing 15 questions) is given at the end of each laboratory experiment/exercise. These are usually multiple choice type questions to evaluate students' perception of each experiment. Small group discussions are also arranged to enhance the level of learning of an experiment. At the end of the course, individual as well as cumulative performances of students' are evaluated based on quizzes.

\subsection{Effectiveness of the course}

The course is evaluated during the mid-semester period and as well as at the end of each semester. Numeric values have been assigned to the various rating scales for the purpose of computing medians. The scale values used are as follows:

$$
\begin{aligned}
\text { Excellent } & =5 \\
\text { Very Good } & =4 \\
\text { Good } & =3 \\
\text { Fair } & =2 \\
\text { Poor } & =1
\end{aligned}
$$

The typical questions used for evaluating the course are:

1. The objectives/learning outcomes for each part of the course were clear.

2. The required tests, quizzes, projects, accurately measured my attainment of these learning outcomes.

3. The course was well organized.

4. The required reading and assignments contributed to my learning

5. The class room discussions contributed to my learning.

6. The instructor inspired interest in the course material.

7. The instructor provided timely feedback.

8. The instructor's feedback was clear and useful.

9. The instructor treated students with respect.

10. The instructor provided opportunities for students to learn from each other.

11. The instructor was available and helpful

This evaluation method has been very useful in assessing and then improving the course contents and methodologies.

"Proceedings of the 2004 American Society for Engineering Education Annual Conference \& Exposition Copyright (C) 2004, American Society for Engineering" 


\section{Conclusions and remarks}

To summarize learning outside technique, the participating lecturers should be made to realize the importance of playing the supporting role and to stay focus on the topic assignments in order to make the entire production unified and outstanding. If possible, the team members should also audit each other's lectures at least once during the semester in order to establish useful connection between individual lessons. It is expected, only this kind of well-coordinated teamwork will bring a rich and colorful educational experience that will benefit both learners and teachers especially on specialty topics like biomaterials.

Team teaching is like running a relay marathon. The members of the team should be well selected to complement each other not only in the area of knowledge and expertise, but also in terms of compatibility of personality and willingness to work as a team.

In order to develop an intuitive feel for material behavior (i.e. understanding micromechanics and failure analysis approaches), "hands on" exposure in material samples and representative devices are CRITICAL. Continuous assessment, discussions and more time spent in the laboratory will reinforce these concepts.

Failure analysis approaches including microhardness/fracture toughness, ball punch deformation test for formability, determination of inclusion content using image analysis technique, provide useful technical information for evaluating merits and demerits of biomaterials.

\section{References}

1. BECHTOL CO, FERGUSON AB, LAING PG: Metals and Engineering. In Bone and Joint Surgery. Baltimore, Williams \& Wilkins, 1959

2. BRETTLE J: A survey of the literature on metallic surgical implants. Injury 2:26, 1970

3. LUDWIGSON DC: Requirements for metallic surgical implants and prosthetic devices. Metals Engineering Quarterly: American Society of Metallurgists 1, 1965

4. MEARS DC: Materials and Orthopedic Surgery. Baltimore, Williams \& Wilkins, 1979

5. RUBIN L: Biomaterials in Reconstructive Surgery. St Louis, CV Mosby, 1983

6. VENABLE CS, STUCK WG: The Internal Fixation of Fractures. Springfield, IL, Charles C Thomas, 1947

7. WILLIAMS DF, ROAF R: Implants in Surgery. Philadelphia, WB Saunders, 1973

8. VANDER VOORT, G.F., Image Analysis, vol 10, $9^{\text {th }}$ ed., Metals Handbook: Materials Characterization, ASM, Metals Park, OH, 1986, pp. 309-322

"Proceedings of the 2004 American Society for Engineering Education Annual Conference \& Exposition Copyright (C) 2004, American Society for Engineering" 


\section{Biography of Dr. K.V. SUDHAKAR}

Dr. K. V. Sudhakar is an Associate Professor-III in the Department of Mechanical Engineering at Universidad de las Americas-Puebla in Puebla, Mexico. He has over 20 years of professional experience in Teaching, Research and Industries. He has worked between 1999-2001 as an Assistant Professor at Western Michigan and Central Michigan Universities in Michigan, USA. Dr. Sudhakar received his Ph.D. degree in Engineering (Fatigue \& Fracture) in 1996 from Indian Institute of Science at Bangalore, M. Tech (Materials \& Metallurgical Engineering) in 1991 from Indian Institute of Technology at Kanpur and B. Tech (Metallurgical Engineering) degree in 1981 from Karnataka Regional Engineering College at Surathkal, in India. Dr. Sudhakar has over 20 peer reviewed technical papers which were published in some of the reputed international journals during the year 1999-2002. He is a technical reviewer for International Journal of Fatigue. Dr. Sudhakar is a recipient of Outstanding Faculty Research Award at Central Michigan University, Michigan (USA) for the academic year 2000-2001. His teaching and research interests include Mechanical Behavior of Materials, Mechanics of Fatigue and Fracture, Biomaterials/Nanomaterials, Materials Processing, Mechanical Testing \& Evaluation, Powder Metallurgy/Metal Injection Molding, Structure-Property Relationship, Materials Science, Failure Analysis and, Physical Metallurgy.

\section{Biography of Dr. TADEUZ MAJEWSKI}

Dr. Tadeuz Majewski is working as a Professor Titular in the Department of Mechanical Engineering at Universidad de las Americas-Puebla in Puebla, Mexico. Dr. Majewski has almost 40 years of Professional experience in Academics, Industires and Research organizations. He obtained his M.Sc. (Mechanical Eng.) degree in 1965 from Warsaw Technical University, Ph.D. degree in 1973 from Warsaw Technical University and D.Sc. in 1996 from Technical University of Poznan, in Poland. His teaching and research interests include Theoretical Mechanics, Theory of Vibrations, Non-linear Oscillations, Theory of Machines and Mechanisms, Theory of Vibration, Mechanical Design, Hydraulic and Pneumatic Systems and Biomaterials.

"Proceedings of the 2004 American Society for Engineering Education Annual Conference \& Exposition Copyright (C) 2004, American Society for Engineering" 